\title{
Conservation, Restoration, and Sustainable Use of Biodiversity Based on Habitat Quality Monitoring: A Case Study on Jeju Island, South Korea (1989-2019)
}

\author{
Hyun-Jung Hong ${ }^{1}\left(\mathbb{D}\right.$, Choong-Ki Kim ${ }^{1, *}$, Hyun-Woo Lee ${ }^{1}$ and Woo-Kyun Lee ${ }^{2}$ (D) \\ 1 Korea Environment Institute, Sejong 30147, Korea; hjhong@kei.re.kr (H.-J.H.); hwlee@kei.re.kr (H.-W.L.) \\ 2 Department of Environmental Science and Ecological Engineering, Korea University, Seoul 02841, Korea; \\ leewk@korea.ac.kr \\ * Correspondence: ckkim@kei.re.kr; Tel.: +82-44-415-7007
}

check for

updates

Citation: Hong, H.-J.; Kim, C.-K.; Lee, H.-W.; Lee, W.-K. Conservation, Restoration, and Sustainable Use of Biodiversity Based on Habitat Quality Monitoring: A Case Study on Jeju Island, South Korea (1989-2019). Land 2021, 10, 774. https://doi.org/ 10.3390/land10080774

Academic Editors: Juan F. Beltrán Pedro Abellán and John Litvaitis

Received: 9 June 2021

Accepted: 20 July 2021

Published: 23 July 2021

Publisher's Note: MDPI stays neutral with regard to jurisdictional claims in published maps and institutional affiliations.

Copyright: (c) 2021 by the authors. Licensee MDPI, Basel, Switzerland. This article is an open access article distributed under the terms and conditions of the Creative Commons Attribution (CC BY) license (https:// creativecommons.org/licenses/by/ $4.0 /)$.

\begin{abstract}
Biodiversity loss is progressing despite biodiversity being essential for human survival, prosperity, and well-being. Conservation, restoration, and sustainable use of the habitat, given that its change is the most prominent factor causing the deterioration of biodiversity, represents a highly effective way of securing biodiversity. Therefore, we assessed and monitored habitat quality as a proxy for biodiversity with habitat quantity in Jeju Island, South Korea. We used an InVEST model with data on the habitat type, suitability, sensitivity, accessibility, and threat factors. Natural habitats throughout Jeju had rapidly decreased in area by $24.9 \%$ from 1989 to 2019 , and this change contributed to the degradation of habitat quality by $15.8 \%$. We provided significant evidence on the critical degradation of habitat for a long period of over 30 years and highlighted the urgent need for policies and behaviors that enhance biodiversity. We proposed appropriate strategies to prompt people to conserve better, restore effectively, and use biodiversity sustainably. We expect that our findings will provide scientific and evidence-based guidance for policy-making on biodiversity enhancement and will further support achievement of the Sustainable Development Goals and Aichi Biodiversity Targets, in addition to compliance with the New Deal for Nature and People.
\end{abstract}

Keywords: land-cover change; habitat quality; InVEST; ecosystem-based approach and assessment; nature-based solution; decision-making support; national park management

\section{Introduction}

Biodiversity is defined as the diversity of organisms arising from land, aquatic, and other complex ecosystems and includes the diversity within species, diversity between species, and ecosystem diversity [1]. Healthy biodiversity is a source of various resources and services necessary to support human survival, prosperity, and well-being [2,3]. Biodiversity is, however, declining globally at a historically fast rate, as a consequence of continued human population and economic growth [4-6]. International societies have recognized the rapid rate of anthropogenic-induced ecological degradation and have encouraged ecosystem-based approaches, scientifically credible assessments of biodiversity, and nature-based solutions [6,7]. Accordingly, individual countries, including parties to the Convention on Biodiversity, aim to assess biodiversity comprehensively and systematically for supporting decision-making based on these assessment results and to prompt public and private actions to ensure that current and future generations are able to use biological resources [6].

Biodiversity is affected by habitat change, presence of invasive species, climate change, overfishing, deforestation, disease, nutrient loading, and pollution [8-10]. A habitat is defined as "the resources and conditions present in an area that produce occupancyincluding survival and reproduction-by a given organism" [11], and habitat change is the most prominent factor causing the deterioration of biodiversity [10,12-14]. Conserving 
habitats quantitatively and qualitatively is a highly effective way of securing the sustenance of biodiversity [15-18]. Habitat quantity can be regarded as the area of a habitat, and habitat quality as the ability of a habitat to provide conditions that facilitate the persistence of a species, a population, or a community in terms of the resources available within a given ecosystem [11]. Habitat quality determines the composition, reproduction, distribution, behavior, and movement of the habitat's species, as well as its maintenance, as it affects the acquisition and usage of resources essential for survival $[19,20]$. Therefore, the enhancement of habitat quality is as necessary as increasing the habitat quantity [21].

However, habitat quality is rarely accounted for sufficiently, when devising biodiversityfocused strategies and action plans, due to the following reasons: limited investigation of habitat quality within specific spaces such as protected areas, insufficient data on factors determining habitat quality, difficulty in quantification by the lack of standard measurement units for habitat quality, complex assessment process of habitat quality, and verification shortage of assessment results. Nevertheless, new approaches [22-33] that evaluate biodiversity in terms of habitat quality have recently been established. Nelson et al. [22], Polasky et al. [23], Terrado et al. [24], Ntshane et al. [25], and Salata et al. [26] assessed and mapped habitat quality. Xu et al. [27] monitored the temporal and spatial evolution of habitat quality. Based on the assessment of habitat quality, Terrado et. al. [28] and Nematollahi et al. [29] identified vulnerable habitats, and Wang et al. [30] and Duarte et al. [31] prioritized habitats for protection. Zhu et al. [32] evaluated the impact of urbanization and landscape pattern on habitat quality. Gibson and Quinn [33] assessed habitat quality using land development scenarios and utilized them for landscape planning. Thus, the authors of the aforementioned studies (1) assessed habitat quality; (2) identified, in advance, significant or vulnerable zones of biodiversity, particularly in relation with development plans; and (3) assisted decision makers in formulating actions to be prioritized for the protection and restoration of biodiversity, as well as for mitigation and adaption to biodiversity loss.

South Korea is under severe developmental pressure, propelled by national, local, and infrastructure development projects designed to meet the needs of its large population, as well as by the prioritization of economic growth. This has resulted in physical changes to habitats and continuous deterioration to their quantity and quality [34]. The country has implemented various policies for the enhancement of biodiversity-containing habitats, such as expanding protected areas, securing habitats, and restoring ecological networks. However, the qualitative improvements in habitats are yet to be realized, principally because of the lack of accurate assessment and proper management of habitat quality. Therefore, we aimed to: (1) examine the land-cover changes having the largest relative negative impact on habitat [6], which occurred between 1989 and 2019 on Jeju Island, South Korea, where rich ecosystems and development pressures coexist; (2) assess the change in habitat quality over 30 years; and (3) propose management plans to improve biodiversity by connecting policy alternatives and application target zones based on these assessment results.

\section{Materials and Methods}

\subsection{Study Area}

Jeju is a volcanic island in South Korea and has a rich natural heritage. It is the only area in the world where various internationally designated protected areas are located within the same location: World Heritage, Biosphere Reserve, Global Geopark, and RAMSAR Wetland. Jeju is inhabited by approximately 4600 species and was recently voted as a Wonder of Nature [35]. Jeju is composed of (1) mountainous, (2) semi-mountainous, (3) low-lying, and (4) coastal zones. Halla Mountain is located in the mountainous zone (from 600 to $1950 \mathrm{~m}$ ) and contains a national park. The national park is surrounded by the semi-mountainous zone (between 200 and $600 \mathrm{~m}$ ) that connects the protected area to the urban district, a low-lying zone (below $200 \mathrm{~m}$; excluding the coastal zone) that predominantly encompasses residential and business districts and a coastal zone that is composed of a tourism and business district (with a standard $500 \mathrm{~m}$ coastline buffer zone) (Figure 1). 


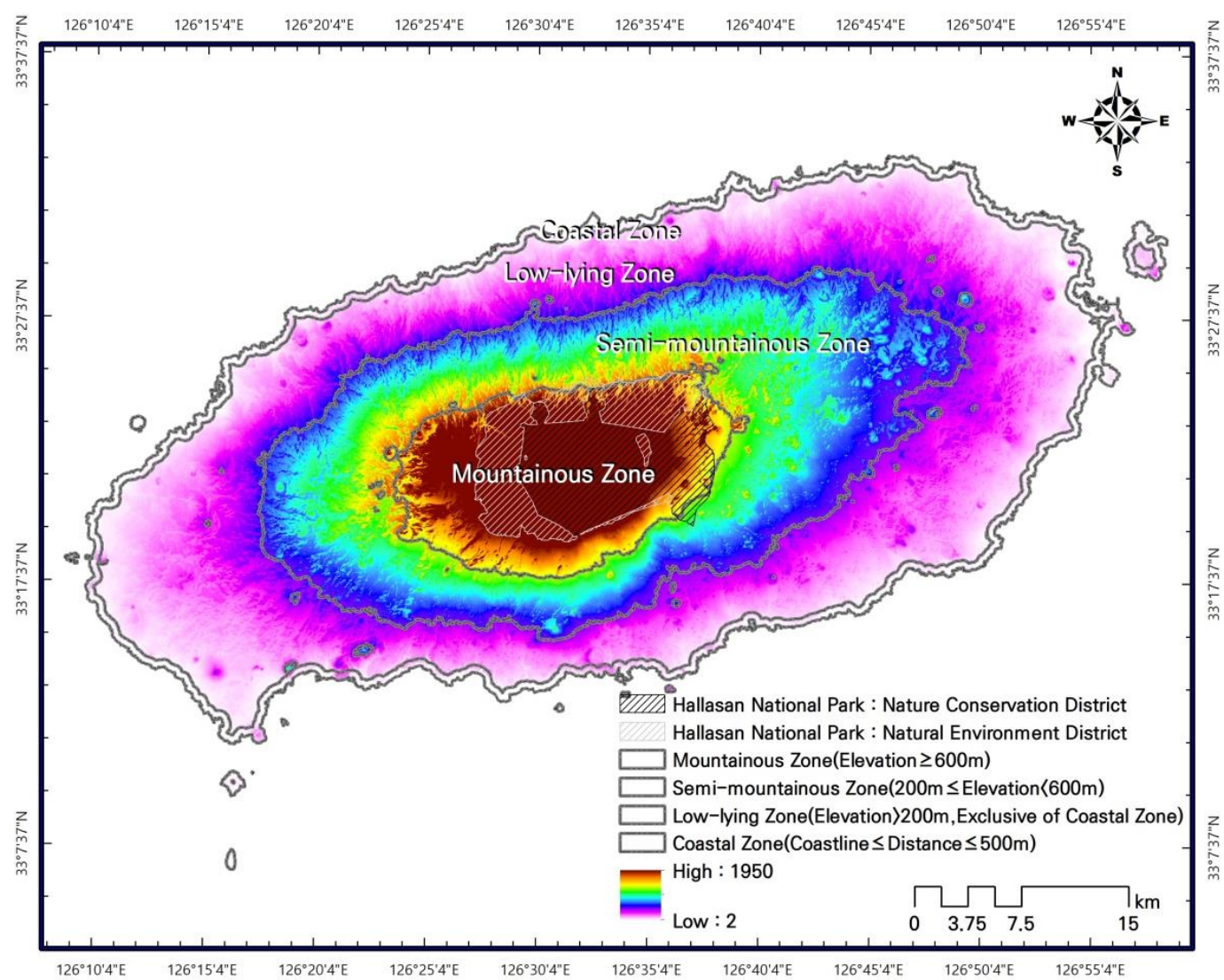

Figure 1. Study area.

The biodiversity of Jeju is subject to social and economic pressures from development that have already adversely affected habitats and damaged biodiversity. This has been exacerbated by the release of green belts that had once prevented urban sprawl and ensured a healthy living environment for citizens through the conservation of the biodiversity surrounding cities [36]. This pressure on biological resources is being intensified by largescale projects and related real estate development in the semi-mountainous, low-lying, and coastal zones. These developments cause a major influx of tourists and immigrants. The resulting demand for biological resources threatens the sustainability of the biodiversity of Jeju.

\subsection{InVEST Habitat Quality Model}

The Natural Capital Project has developed a decision-making support software model, named InVEST (Integrated Valuation of Environmental Services and Tradeoffs; copyright by Natural Capital Project; version 3.9.0), which is based on the assessment of the services provided by ecosystems and biodiversity [37]. InVEST assesses habitat quality within a spatial context by combining habitat types with threat factors, to evaluate the spatial extent and degradation of a habitat. We used a corresponding model for habitat quality assessment governed by Equation (1), where habitat suitability $\left(\mathrm{H}_{\mathrm{j}}\right)$ was converted to a numerical value $\left(Q_{x j}\right)$ using a half-saturation function, thereby scoring the degree of the threat of habitat degradation $\left(D_{x j}\right)$.

$$
Q_{x j}=H_{j}\left(1-\left(\frac{D_{x j}^{z}}{D_{x j}^{z}+k^{Z}}\right)\right)
$$

where $Q_{x j}$ represents the habitat quality in grid cell $x$ with land use/land cover (LULC) type $j ; H_{j}$ represents the habitat suitability with LULC type $j$ for survivability of a species, a 
population, or a community; $D_{x j}$ represents the impact of threats on habitat in grid cell $x$ with LULC type $j ; z$ represents the scaling constant (2.5); and $k$ represents the half-saturation constant (0.5).

\subsection{Construction of Input Data}

Habitat quality is affected by habitat type, habitat suitability, factors threatening habitat quality, habitat sensitivity to threat factors, and habitat accessibility $[28,33,34]$. Habitat type was categorized as water, urban land, barren land, wetland, grassland, forest land, and agricultural land. Habitat suitability ( 0.00 (uninhabitable)- 1.00 (ideally habitable)) for each habitat type was set based on literature review $[24,38,39]$ and local conditions (Table 1). We set the habitat suitability to consider characteristics of Jeju based on a field survey and an interview with local experts, while ensuring, as much as possible, that the range of values used in existing research is not exceeded. The habitat suitability of forest land, habitable for wildlife due to the presence of various resources, and that of urban land, uninhabitable for wildlife due to the predominance of human activities, was set at 0.86 and 0.00 , respectively. Agricultural land provides habitat space and food for wildlife. In South Korea, however, agricultural practices are typically intensive, and generally, have a detrimental effect on ecosystems and biodiversity. Accordingly, the suitability of agricultural land was set at 0.30 , which was lower than that of grassland.

Habitats are altered by farming, urbanization, development, deforestation, natural disasters, and pollution [12]. We selected agriculture, urbanization, building of roads, forest fragmentation, vulnerability to natural disasters, and pollution treatment facilities as the elements threatening habitat quality and constructed these as spatial data. Agricultural land, urban land, and roads were identified from a land-cover map (issued by the Ministry of Environment, South Korea). Fragmented forests were constructed by extracting fragmented areas of less than 10 ha from the forest patches that were previously larger than 10 ha in area, based on a time-series analysis of land-cover maps $(1989,2019)$. In South Korea, forest patches 10 ha in area do not act as base habitats for the stable inhabitation of wildlife, but they serve as ecological stepping stones where wildlife rest while migrating or where they come to for food [40,41]. Areas that have been designated as districts requiring improvements to prevent natural disasters or have a history of flooding were selected as areas vulnerable to disasters. We selected sewage treatment plants, wastewater disposal plants, wastewater treatment plants, filtration plants, waste disposal facilities, and landfills as pollution treatment facilities. As in the case of habitat suitability, we established the properties (relative intensity, maximum impact distance, and type of decay based on distance) of threats to habitat sensitivity, to decisively analyze the impact on habitat sensitivity of these threats, based on literature review $[24,38,39]$ and assessment of the local condition (Table 1).

Protected areas in South Korea are designated in keeping with laws specific to the area of interest. Wetland protection areas, specified islands, natural parks, natural monument designation areas, absolute preservation areas, ecosystem preservation areas, river zones, water source protection areas, green zones, and preserved mountainous areas are public interest areas for the conservation of biodiversity. Habitat accessibility for these areas can be categorized according to the level of acceptable activity and restricted access, as stipulated in the area-specific laws. We set the accessibility value of each protected area based on individually categorized levels of protection and usage intensity. We set the accessibility of strictly protected areas as 0.1 and that of non-protected areas as 1.0. 
Table 1. Habitat suitability and habitat sensitivity to threat factors on Jeju, South Korea.

\begin{tabular}{|c|c|c|c|c|c|c|c|}
\hline \multirow[b]{2}{*}{$\begin{array}{l}\text { Habitat } \\
\text { Type }\end{array}$} & \multirow[b]{2}{*}{$\begin{array}{c}\text { Habitat } \\
\text { Suitability }\end{array}$} & \multicolumn{6}{|c|}{ Sensitivity ${ }^{2}$ to Threat Factors by Habitat Type } \\
\hline & & $\begin{array}{c}\text { Agriculture } \\
(0.57,3.40, \text { Linear })^{3}\end{array}$ & $\begin{array}{c}\text { Urbanization } \\
\quad(0.88,5.90 \\
\text { Exponential })^{3}\end{array}$ & $\begin{array}{c}\text { Roads } \\
(0.59,2.40, \text { Linear })^{3}\end{array}$ & $\begin{array}{c}\text { Forest } \\
\text { Fragmentation } \\
(0.43,1.50, \text { Exponential })^{3}\end{array}$ & $\begin{array}{c}\text { Vulnerability } \\
\text { to Natural Disasters } \\
(0.40,1.20, \text { Linear })^{3}\end{array}$ & $\begin{array}{c}\text { Pollution Treatment } \\
\text { Facilities } \\
(0.50,5.00, \text { Linear })^{3}\end{array}$ \\
\hline Water & $\begin{array}{c}0.65 \\
(0.65-1.00)^{4}\end{array}$ & $\begin{array}{c}0.65 \\
(0.51-0.78)^{4}\end{array}$ & $\begin{array}{c}0.73 \\
(0.35-0.91)^{4}\end{array}$ & $\begin{array}{c}0.55 \\
(0.24-0.73)^{4}\end{array}$ & 0.00 & 0.28 & 0.73 \\
\hline $\begin{array}{l}\text { Urban } \\
\text { Land }\end{array}$ & $\begin{array}{c}0.00 \\
(0.00-0.30)^{4}\end{array}$ & $\begin{array}{c}0.00 \\
(0.16)^{4}\end{array}$ & $\begin{array}{c}0.00 \\
(0.00-0.01)^{4}\end{array}$ & $\begin{array}{c}0.00 \\
(0.00-0.10)^{4}\end{array}$ & 0.00 & 0.00 & 0.00 \\
\hline Wetland & $\begin{array}{c}0.70 \\
(0.60-0.70)^{4} \\
\end{array}$ & $\begin{array}{c}0.75 \\
(0.30-0.70)^{4} \\
\end{array}$ & $\begin{array}{c}0.70 \\
(0.20-0.30)^{4} \\
\end{array}$ & $\begin{array}{c}0.55 \\
(0.10)^{4} \\
\end{array}$ & 0.00 & 0.28 & 0.65 \\
\hline Grass land & $\begin{array}{c}0.42 \\
(0.30-0.80)^{4}\end{array}$ & $\begin{array}{c}0.46 \\
(0.20-0.67)^{4}\end{array}$ & $\begin{array}{c}0.45 \\
(0.20-0.80)^{4}\end{array}$ & $\begin{array}{c}0.33 \\
(0.20-0.70)^{4}\end{array}$ & 0.00 & 0.45 & 0.00 \\
\hline Forest Land & $\begin{array}{c}0.86 \\
(0.50-1.00)^{4}\end{array}$ & $\begin{array}{c}0.66 \\
(0.10-0.70)^{4}\end{array}$ & $\begin{array}{c}0.75 \\
(0.20-0.90)^{4}\end{array}$ & $\begin{array}{c}0.52 \\
(0.20-0.78)^{4}\end{array}$ & 0.45 & 0.78 & 0.00 \\
\hline
\end{tabular}

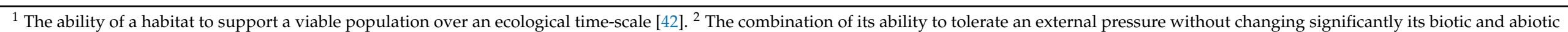

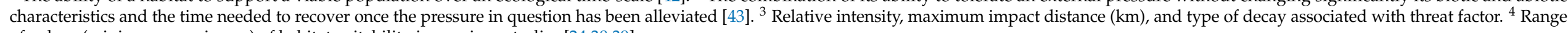
of values (minimum-maximum) of habitat suitability in previous studies $[24,38,39]$. 


\subsection{Habitat Quality Assessment}

We assessed habitat quality throughout Jeju by running the model using our input data. As biodiversity of Jeju has different characteristics according to elevation, we categorized the physical geography of the island into mountainous, semi-mountainous, low-lying, and coastal zones according to altitude (Figure 1) and analyzed the habitat quality for each zone.

The Ministry of Environment, South Korea conducted a field investigation of topography, geology, natural landscapes, green zones, vegetation, and soil, as a part of efforts toward the conservation of biodiversity. This investigation involved a demarcation of the spots where wildlife, including mammals, birds, reptiles, amphibians, fish, insects, and benthic invertebrates, was found. We used the average habitat quality of locations where wildlife was found as a criterion for designating habitats with high quality or low quality. We categorized Jeju based on the average (reference) value of habitat quality in identified sites as follows: areas with habitat quality above 0.56 had favorable habitat quality and were categorized as "conservation zones", whereas areas with habitat quality below 0.56 required improvements to prevent a decline in biodiversity and were categorized as "management zones".

\subsection{Habitat Quality Verification}

An environmental conservation value assessment map (issued by Ministry of Environment, South Korea) rates land according to its environmental value. It is based on assessments of nationally integrated environmental information and the ranking of items (protected area, diversity, natural characteristics, richness, rarity, fragility, stability, and connectivity) in natural (ecosystem, natural scenery, etc.), living (air, water, soil, etc.), and human/social environments. It is primarily used for land management. First-grade zones on this map are marked as top priority conservation areas, where no development activities are permitted, and only ecological restoration projects can be implemented. Second-grade zones are marked as priority conservation areas, where only small-scale development activities can be implemented. Third-grade zones are marked as main conservation areas, where conditional development is permitted. Fourth-grade zones are marked as already developed or developing areas, where conservation is accomplished partially. Fifth-grade zones are permitted development areas.

An ecological and natural map (issued by Ministry of Environment, South Korea) rates the natural environment of a region, detailing mountains, rivers, inland wetlands, lakes, farmland, and cities according to the ecological, natural, and landscape values. It is generated through field investigation assessments and the ranking of items (vegetation, endangered wildlife, wetlands, and topography) in the natural environment and is used for planning and implementing national/local land use. Separately managed zones on this map are protected areas that have historical, cultural, or landscape significance, or are designated for the conservation of urban green spaces. First-grade zones, which become the major habitats, ecological networks, or ecological corridors for endangered wildlife, require the protection and restoration of natural environments. Second-grade zones, which are areas outside first-grade zones, are required to protect first-grade zones, and use of the natural environment within these zones is permitted for conservation activities or controlled development activities. Third-grade zones comprise all other areas and development activities are permitted in these zones.

We used these maps to verify the reliability of habitat quality assessment results in pixel units $(30 \times 30 \mathrm{~m})$. We derived Spearman correlation coefficients between model assessment results and these verification maps issued officially by the central government using R software (version 4.1.0). Based on these coefficients, we analyzed the extent to which the conservation zones and the management zones corresponded spatially with the first-, second-, and third-grade zones and with the fourth- and fifth-grade zones, respectively, on the environmental conservation value assessment map. For the additional verification of the habitat quality of the conservation zones, a comparative analysis was 
conducted based on the separately managed zones and the first- and second-grade zones of the ecological and natural map.

\section{Results}

\subsection{Land-Cover Change between 1989 and 2019}

Human-induced change, including land use change and exploitation of biological resources, has had the largest negative impact on biodiversity since 1989. Between 1989 and 2019, overall changes in the area of each land-cover type showed that urban land and agricultural land had increased 1.7- and 0.6-fold, respectively, and that grassland and forest land had decreased 0.3- and 0.2-fold, respectively (Figure 2). In the mountainous zone, forest land constituted $89.6 \%$ of the land in 2019 , and there were no significant changes to land-cover types over the last 30 years, in terms of legal management based on the Natural Parks Acts. In the semi-mountainous area, the proportion of forest land in 2019 was $51.2 \%$, which was similar to the proportion recorded in 1989. However, urban and agricultural land had increased 6.0- and 0.2-fold, respectively, while grassland had decreased 0.2 -fold. In the low-lying zone, there had been a rapid change in land-cover due to productive, economic, and recreational activities. Urban land and agricultural land showed a large increase (1.5- and 0.8-fold, respectively), whereas grassland and forest land showed a marked decline (0.4- and 0.6-fold, respectively). In the coastal zone, urban land had increased 1.3-fold, while grassland and forest land had decreased 0.1- and 0.5-fold, respectively.

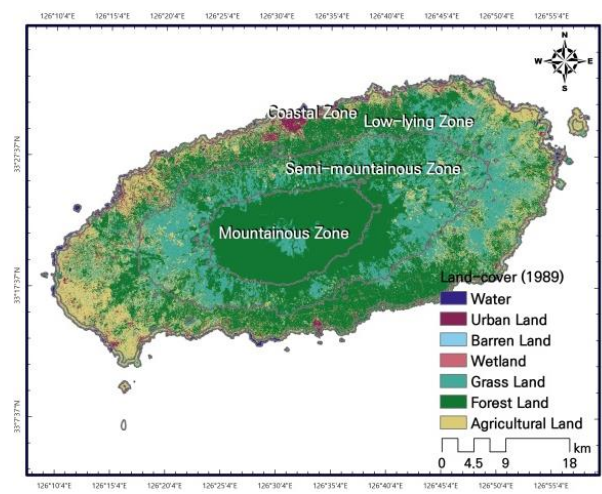

(a)

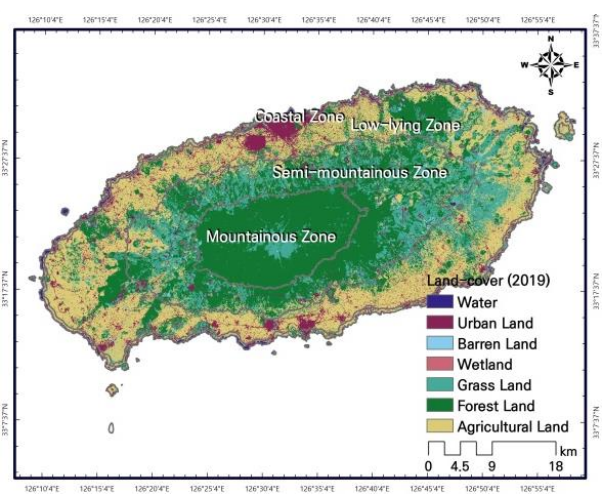

(b)

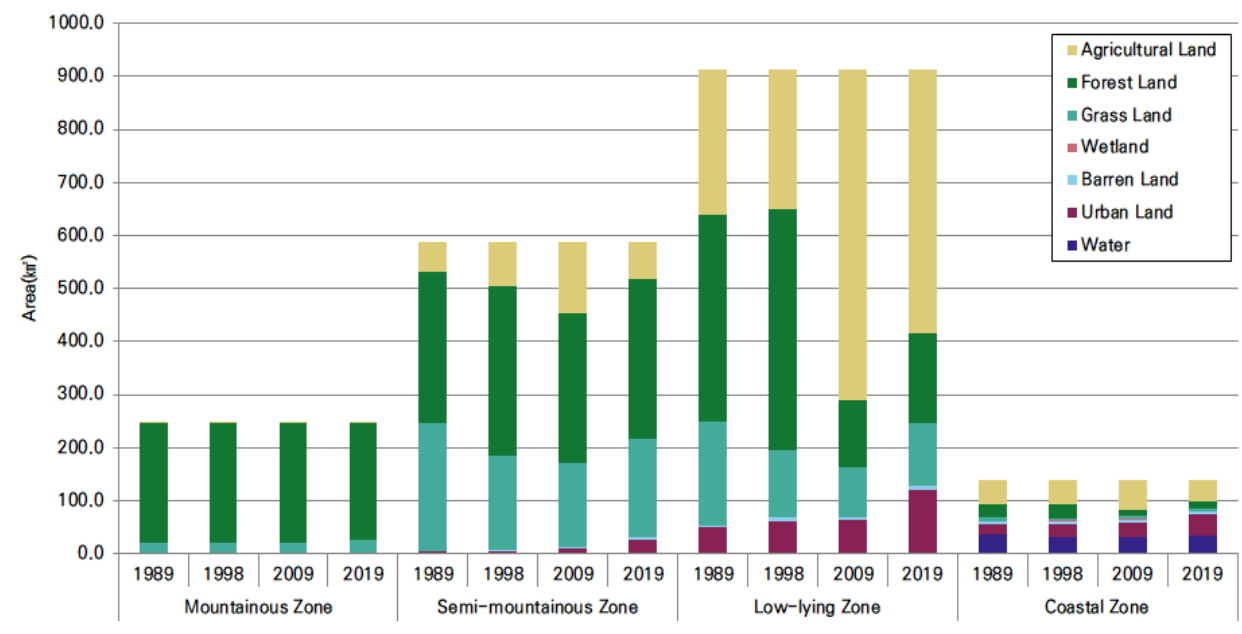

(c)

Figure 2. Changes in land-cover on Jeju, South Korea. (a) Distribution of land-cover types in 1989. (b) Distribution of land-cover types in 2019. (c) Changes in land-cover. 


\subsection{Habitat Quality Change between 1989 and 2019}

The negative trend in land-cover change has contributed to worsening habitat quality. The average habitat quality on Jeju was 0.60 in 2019 and declined 0.2-fold from 1989 to 2019. The habitat quality of the conservation zones also decreased 0.2 -fold, and $21.0 \%$ of the island changed from a conservation zone to a management zone (Figure 3). In the mountainous zone, average habitat quality was maintained at 0.82 from 1989 to 2019 . The conservation zones underwent little change, and the management zones underwent a 0.3 -fold increase. In the mountainous zone, $51.6 \%$ of the area showed a decline in habitat quality. In the semi-mountainous zone, the average habitat quality declined from 0.62 in 1989 to 0.61 in 2019, impacting $70.9 \%$ of the area in this zone. The conservation and management zones showed a 0.1 -fold increase and a 0.1 -fold decrease in habitat quality, respectively. In the low-lying zone, the average habitat quality declined from 0.55 in 1989 to 0.38 in 2019 , impacting $83.0 \%$ of the area in this zone. The conservation zones underwent a 0.6-fold decrease in cover, while the management zone cover increased 0.4-fold. Over this time, $7.5 \%$ of the area was upgraded from a management zone to a conservation zone, whereas $31.3 \%$ was downgraded from a conservation zone to a management zone. In the coastal zone, the average habitat quality continuously decreased 0.3-fold from 0.46 in 1989 to 0.33 in 2019 , impacting $64.3 \%$ of the area in this zone. The conservation and management zones underwent a 0.2 -fold decrease and a 0.2 -fold increase, respectively. In the coastal zone, $5.0 \%$ of the area was upgraded from a management zone to a conservation zone, whereas $16.5 \%$ was downgraded from a conservation zone to a management zone.

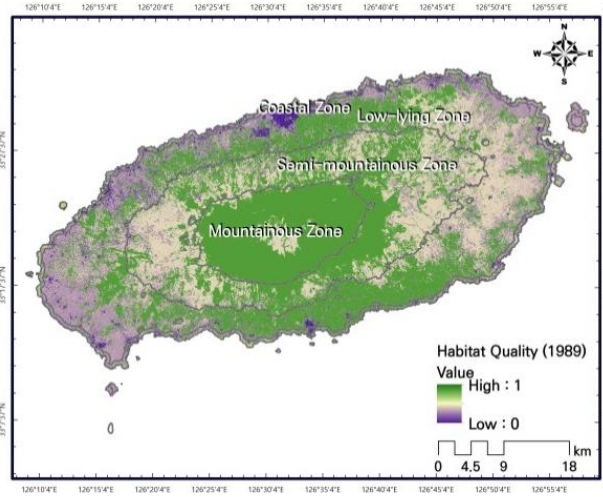

(a)

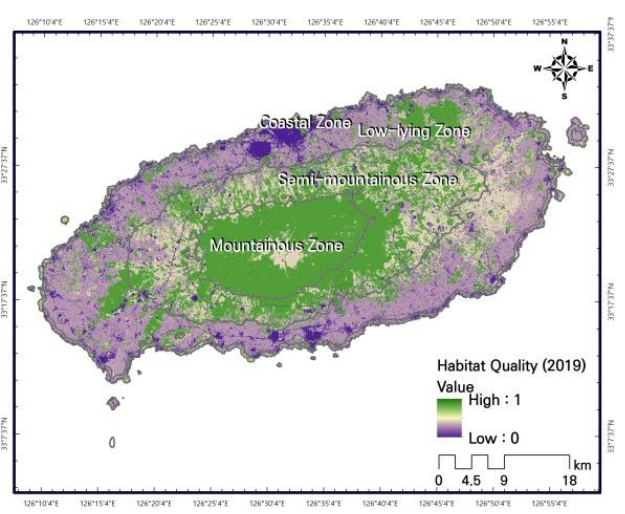

(b)

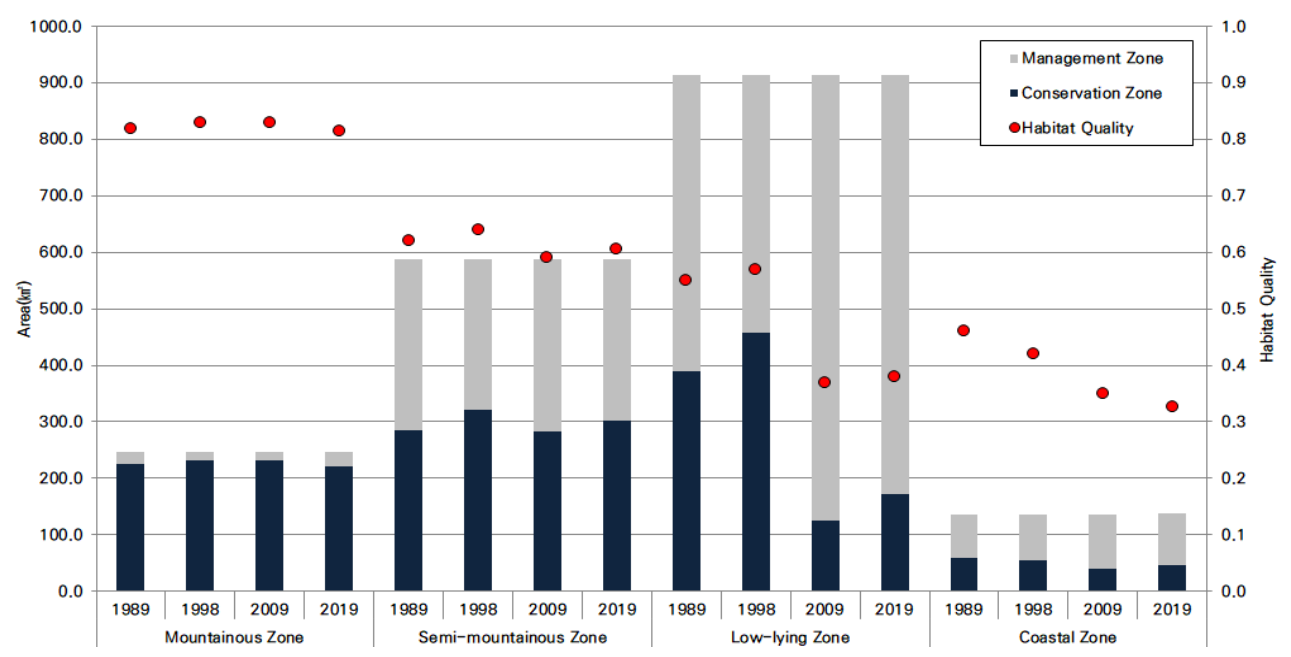

(c)

Figure 3. Changes in habitat quality on Jeju, South Korea. (a) Distribution of habitat quality in 1989. (b) Distribution of habitat quality in 2019. (c) Changes in habitat quality. 


\subsection{Reliability of Habitat Quality Assessments}

Statistical analysis showed that the results of habitat quality assessment for 2019 correlated with the environmental conservation value assessment map value of 0.45 , as well as the ecological and natural map value of 0.59 (Table 2). Conservation zones recorded for 2019 showed $56.9 \%$ consistency with the first-, second-, and third-grade zones of the environmental conservation value assessment map. However, the conservation zones recorded for 2019 were $76.5 \%$ consistent with the first-grade, second-grade, and separately managed zones of the ecological and natural map, supporting the validity of our findings. Management zones showed $86.1 \%$ consistency with the fourth- and fifth-grade zones of the environmental conservation value assessment map.

Table 2. Spearman correlation coefficient between the results of habitat quality assessment and verification materials of Jeju, South Korea.

\begin{tabular}{cccc}
\hline & Habitat Quality & ECVAM $^{*}$ & $\begin{array}{c}\text { Ecological and } \\
\text { Natural Map }\end{array}$ \\
\hline Habitat quality & 1.00 & 0.45 & 0.59 \\
\hline ECVAM $^{*}$ & 0.45 & 1.00 & 0.53 \\
\hline $\begin{array}{c}\text { Ecological and } \\
\text { natural map }\end{array}$ & 0.59 & 0.53 & 1.00 \\
\hline Number of observations $=2,098,074 ; p$-value $<0.0001 .{ }^{*}$ ECVAM: environmental conservation value assessment map.
\end{tabular}

\section{Discussion}

Jeju was found to have a higher habitat quality, compared to other spots where wildlife has been found. This insight triggered rapid land-use changes related to development and tourism (Figure 2). The presence of man-made habitats, including agricultural land, barren land, and urban land, has rapidly increased in extent over the last 30 years, whereas that of natural habitats, including forest land, grassland, wetland, and water, has rapidly decreased. These might be the primary drivers associated with damage to biodiversity on the island (Figure 3). Local residents are also wary of the increasing scale of the aforementioned social and environmental effects due to economic development and support the need for the sustainable management of biodiversity. In a survey conducted among Jeju's residents (September 2015; 120 respondents), 60.2\% of the respondents agreed that natural resources need to be protected by immediately implementing appropriate measures, rather than maintaining the status quo through the continuation of existing policies $(29.6 \%)$, or development for the sake of economic growth (10.2\%) [44]. The local government is devising and executing various policies to enhance biodiversity, reflecting the local residents' demands; survey, protection, conservation, expansion, restoration, control, restriction, nationalization, monitoring, research, education, ecotourism, and collaboration [45] (Figure 4).

Despite these efforts by the local government, policy effect has not been achieved due to the disconnection between policy alternatives and their application target zones based on scientific assessments and monitoring. International societies have encouraged policy decision-making based on scientific assessments for habitat, landscape, ecosystem, and biodiversity management [6,7]. However, this has yet to be realized at the local level in South Korea, owing to the lack of personnel, budget, skill, and experience. The identification of excellent or vulnerable spaces for biodiversity $[46,47]$ and the establishment of countermeasures to improve biodiversity $[45,48]$ have been conducted individually. The only habitats to have been properly linked with policy, considering spatial characteristics, are the specific habitats for natural monuments (cactuses) or endangered species (Azolla japonica) [49,50], or other specific protected areas [51-53]. Our study findings can be incorporated systematically in policy decision-making by scientifically quantifying the status of, and change in, habitat quality as a proxy for biodiversity, as well as by spatially connecting these results with policy reform. We suggest the following approaches as 
potential solutions for the biodiversity management of Jeju, based on habitat quality monitoring (Figure 4).

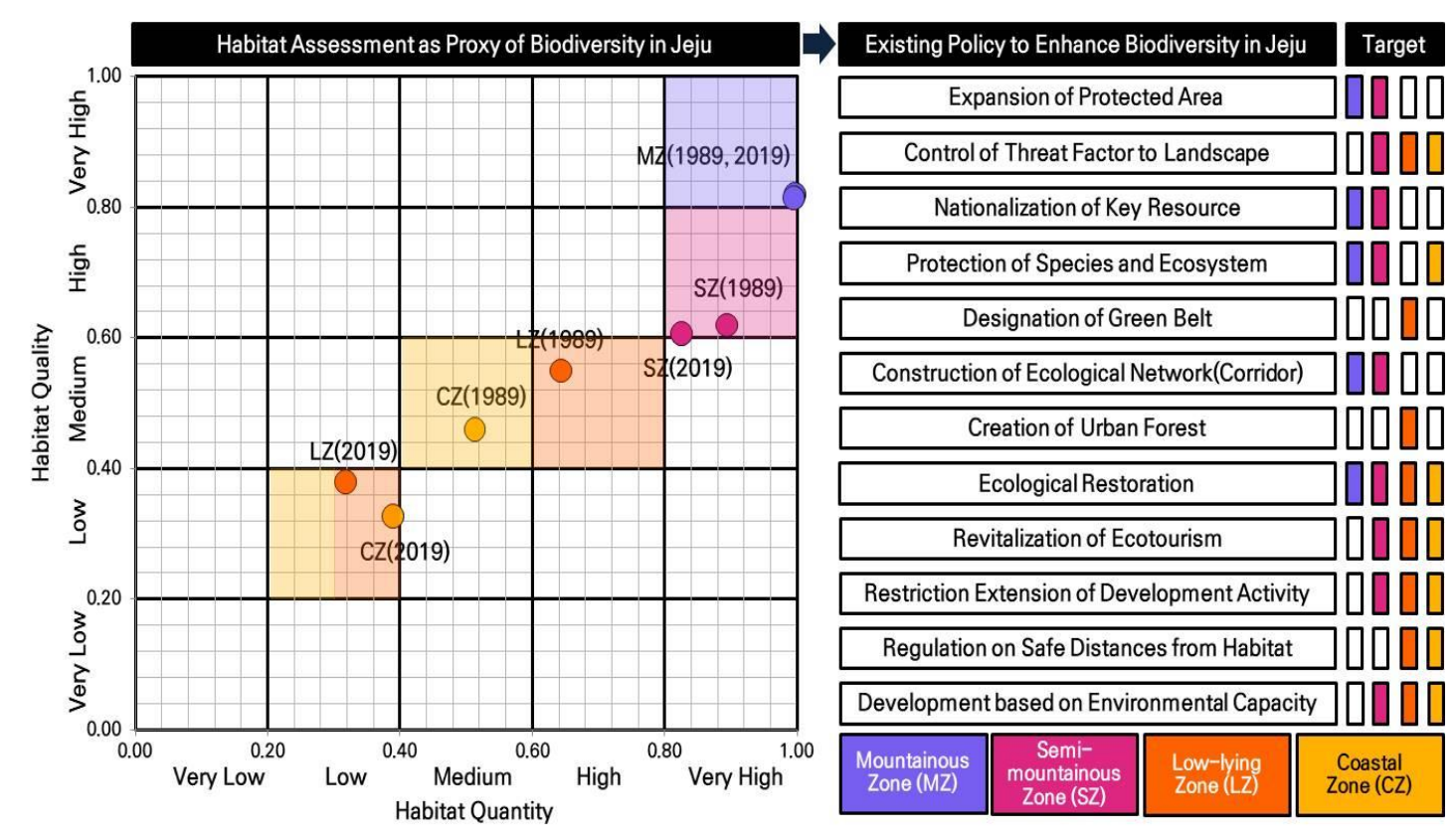

Figure 4. Connection between existing policy alternatives and application target zones based on habitat quality assessment and monitoring for the improvement of biodiversity in Jeju, South Korea.

The habitat quantity (defined for natural habitats in this; forest land, grassland, wetland, and water) and the habitat quality of the mountainous zone were very high and had not undergone much change, owing to legislation-based strict management. However, over the 30-year period, the habitat quality in the zone had declined to half. Thus, the expansion of protected areas, nationalization of key resources, protection of species and ecosystems, construction of ecological networks, and restoration of ecosystems should be selected as areas requiring stronger conservation policies for biodiversity. Both the habitat quantity and the habitat quality of the semi-mountainous zone were very high and had undergone minimal change. However, the habitat quality had declined over more than $70 \%$ of this zone due to the large-scale investment into tourism-related land development and the construction of tourist complexes, golf courses, and amusement parks. Policies must be urgently implemented to consider the expansion of protected area, control of threats to the landscape, nationalization of key resources, protection of species and ecosystems, construction of ecological networks, restoration of ecosystems, revitalization of ecotourism, restriction extension of development activities, and development based on environmental capacity. The habitat quantity and the habitat quality of the low-lying zone were low and had undergone major degradation, with the habitat quality having declined across more than $80 \%$ of this zone, owing to intensive developmental activities and rapid increase in land area allocation for residential development, tourism, and economic activity. Policies that can be used to mitigate the effects of increasing developmental activities are as follows: control of threat factors to landscape; designating a green belt; creation of urban forests; restoration of ecosystems; revitalization of ecotourism; restriction extension of development activities; regulation on safe distances from habitat; development based on environmental capacity. The habitat quantity and the habitat quality of the coastal zone were low and had undergone moderate decline, with habitat quality having declined over more than $60 \%$ of this zone, owing to the construction of coastal roads and encroachment of the shoreline. Primary policy interventions should focus on the control of threat factors to the landscape, protection of species and ecosystems, restoration of ecosystems, revitalization 
of ecotourism, restriction extension of development activities, regulation on safe distances from habitat, and development based on the environmental capacity.

The mountainous zone is rich in tropical, temperate, cold temperate, and cold species. Particularly, Halla Mountain National Park is an important habitat of the mountainous zone for protection of its notably rich biodiversity, undamaged natural ecosystem, and spectacular scenery. At this park, only minimal measures are allowed for scientific research or the conservation of nature, as per the Natural Parks Act. Additionally, the construction of park facilities, in accordance with limited standards, is permitted at this park. However, with the abolishment of a park entrance fee and designation of the park as an international protected area, there has been a rapid increase in the number of visitors. Consequently, a portion of it was released from protected status and has been allocated for construction and development, and thus, the biodiversity of the mountain is under growing pressure. Based on the results of the present study, significant evidence supporting critical degradation of the habitat can be provided. Habitat quantity of the park decreased from $99.89 \%$ in 1989 to $99.62 \%$ in 2019, showing negligible change, while the habitat quality of the park decreased from 0.82 in 1989 to 0.80 in 2019, impacting 8.5\% of the park. Given this situation, we propose the following strategies for protecting, conserving, restoring, controlling, and utilizing biodiversity of Halla Mountain Park, based on habitat quality monitoring (Figure 5).

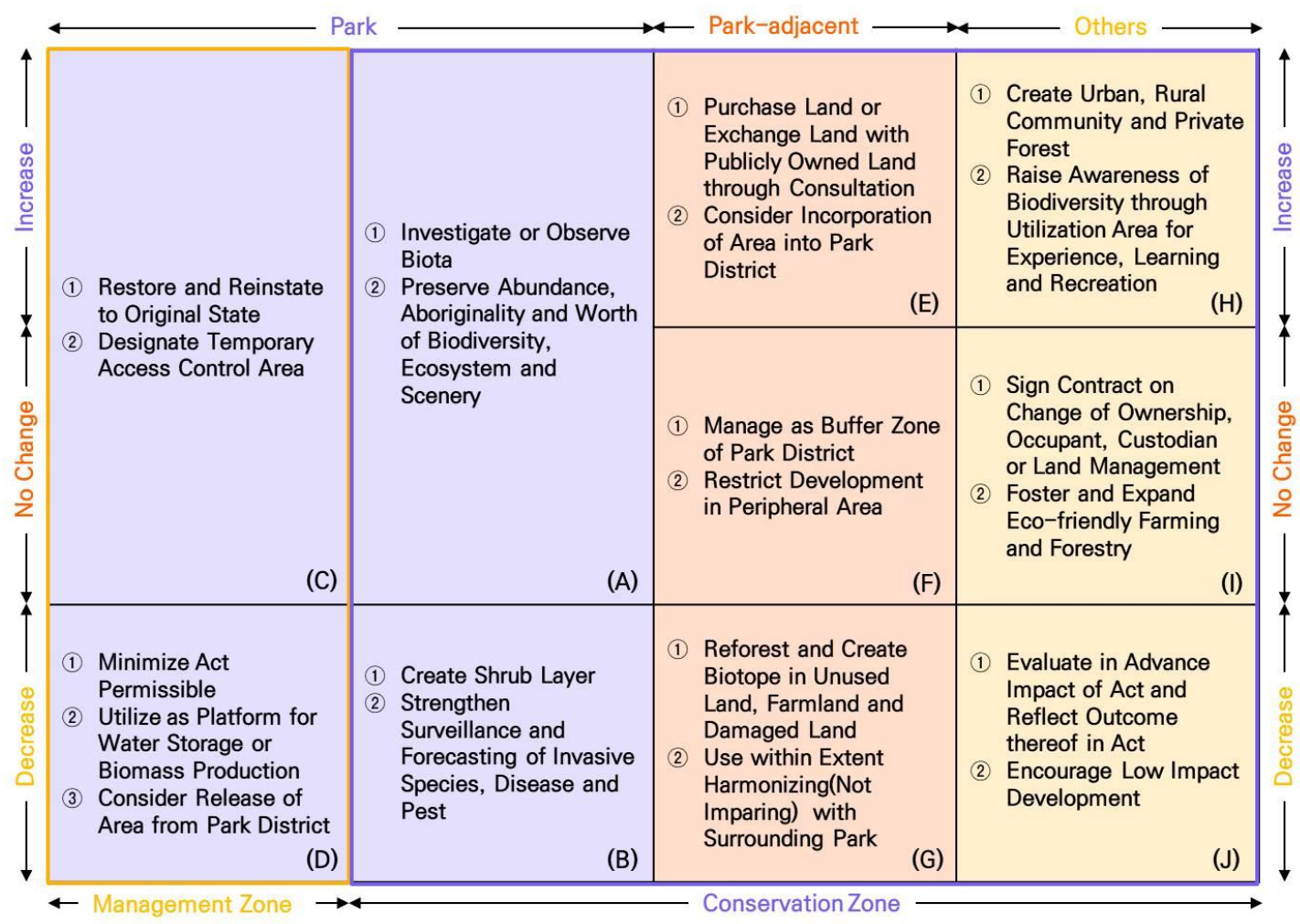

Figure 5. Biodiversity conservation and management strategies for Halla Mountain National Park, based on habitat quality assessment and monitoring in Jeju, South Korea.

The management strategies for the Halla Mountain National Park to preserve and promote the sustainable utilization of biodiversity are as follows. First, a scientific and specialized investigation on the status and characteristics of the topography, ecosystem, biodiversity, and scenery should be conducted over a long term in the areas where habitat quality has improved or has subsequently been maintained as conservation zones within the park district (A). The preservation of the abundance, aboriginality, and worth of the ecosystem, biodiversity, and scenery should be implemented for the long term, based on the 
aforementioned investigations in this area (A). Second, habitat threats should be mitigated by creating a shrub layer and strengthening surveillance for invasive species, disease, and pests, particularly in the conservation zones where habitat quality has diminished within the park district (B). Third, a special protection area or temporary access control area should be designated to prohibit the access of visitors or the passage of vehicles over the area for a fixed period, and the destroyed biodiversity should be restored to its original state in areas where habitat quality has been maintained or increased as management zones within the park district (C). Fourth, the activities permissible in these areas, including the construction of facilities, should be minimized, with retaining activities required for national defense, public interest, and safety of visitors, where habitat quality has diminished, as management zones, including areas bordering the boundary the park (D). In addition, the utilization as a platform for water storage or biomass production, or the release from the park district should be considered in these areas (D).

Potential management strategies for non-park districts or areas neighboring park districts are as follows. First, conservation zones where the habitat quality has improved should be purchased or exchanged with publicly owned land through consultations and land transactions with owners (E). Such areas should be incorporated into a park district when validity is ascertained through examination of the feasibility of the park district (E). Second, in conservation zones where the habitat quality has been maintained, a park buffer zone should be created to restrict development activities in peripheral areas (F). Third, in conservation zones where habitat quality has diminished, the unused, arable, and damaged lands should be reforested to create a designated biotope (G). This area should be used in union with the surrounding park, without impairment of the scenery and the ecological and cultural environments of the park $(\mathrm{G})$.

Management strategies suggested for locations outside of these areas are as follows. First, in conservation zones where habitat quality has improved, urban eco-villages, private forests, and field programs should be created to enhance public awareness on the conservation of biodiversity and on the adoption of environmental-friendly practices $(\mathrm{H})$. Second, conservation zones where habitat quality has been maintained should be protected as wildlife habitats, if necessary, through contracts detailing regulations related to change in the owner, occupant, and custodian, or in the land management methods (the cultivation of land, use of chemical materials, and creation of wetlands) (I). Eco-friendly farming and forestry practices should be instituted and expanded upon in this area (I). Third, in conservation zones where habitat quality has declined, regulations should be implemented to evaluate, in advance, the impact of land use on biodiversity and to only permit low-impact development (J).

\section{Conclusions}

There has been a significant increase in public awareness on biodiversity, as well as on its importance to the quality of life of human beings. However, biodiversity is still being lost and degraded, and many of nature's contributions to humans are being compromised [4-6]. Policy-making and implementation, based on scientific and systematic assessment of biodiversity, could lead to adoption of best practices, including the conservation, restoration, and sustainable use of biodiversity. This would, in turn, contribute to the achievement of the Sustainable Development Goals and the Aichi Biodiversity Targets, in addition to compliance with the New Deal for Nature and People. Accordingly, international societies intend to provide scientifically credible and independent up-to-date assessments of biodiversity using indices to realize evidence-informed policy decisions and actions [6,7]. However, prevalent indices used to assess biodiversity, such as the Mean Species Abundance, Living Planet Index, and National Biodiversity Index, which are used in formulating biodiversity strategies, are not sufficient for the qualitative consideration of biodiversity. Habitat quality assessment allows for complex factors that contribute to long-term biodiversity degradation to be identified and adequately informs policy making, as the habitat quality is defined as the ability of a habitat to provide conditions that facilitate 
the persistence of a species, a population, or a community with available resources within a given ecosystem [11]. Therefore, we assessed the status and trends of habitat quality with land-cover change as a proxy for biodiversity, and proposed strategies that should be considered to conserve biodiversity comprehensively and systematically and to use biological resources sustainably.

Jeju, South Korea, where various protected areas are located, includes a national park, a wetland protection area, and a specified island, among others, thereby encompassing a region with both rich biodiversity and rapid development pressures. A habitat-focused scientific study is urgently needed to identify viable solutions and to formulate appropriate biodiversity management schemes. We monitored the change in habitat quality with landcover change between 1989 and 2019 in Jeju. We provided detailed evidence regarding critical degradation of the habitat over a long period. We found that natural habitats throughout Jeju had rapidly decreased by $24.9 \%$, from 1989 to 2019 , and this change contributed to the degradation of the habitat quality by $15.8 \%$. Using this information, we elucidated significant evidence on the critical degradation of biodiversity over a long period and highlighted the urgent need for policies and behaviors to enhance biodiversity. We proposed appropriate policy measures that could prompt people to conserve better, restore effectively, and use biodiversity sustainably, based on the accumulated knowledge gathered through the aforementioned assessment. These findings can also be used to trigger a shift in focus from the quantitative to qualitative aspects, with respect to decision-making on biodiversity management, which could result in improvement of biodiversity.

Detailed analyses of how biodiversity interacts holistically with pressure/status/trends/ resilience in habitats, conducted in line with the advice of interdisciplinary expert panels, working groups, and committees, are required for each habitat type. Professional reviews, between habitat quality and factors affecting habitat quality, should be conducted based on the significance test, and the reliability of habitat quality assessments should be enhanced based on various verification data. The prediction of changes to habitat quality based on various scenarios that reflect past, current, and future conditions can assist policy and decision makers in devising more strategic and timely policy-based interventions to sustain biodiversity, which safeguards socio-economic welfare. Based on the aforementioned contributions, we believe that the results of our study can improve international indices used for the quantitative assessment of biodiversity, provide scientific and evidence-based guidance for policy-making on biodiversity enhancement, and support the achievement of the global vision, which is living in harmony with nature.

Author Contributions: Conceptualization, H.-J.H. and C.-K.K.; methodology, H.-J.H., C.K-K., and W.-K.L.; software, H.-J.H. and C.-K.K.; validation, H.-J.H., C.-K.K., and W.-K.L.; formal analysis, H.J.H., C.-K.K., and H.-W.L.; investigation, H.-J.H., C.-K.K., and H.-W.L.; resources, H.-J.H. and C.-K.K.; data curation, H.-J.H. and C.-K.K.; writing-original draft preparation, H.-J.H.; writing-review and editing, H.-J.H., C.-K.K., H.-W.L., and W.-K.L.; visualization, H.-J.H.; supervision, C.-K.K. and H.-W.L.; project administration, H.-W.L.; funding acquisition, H.-W.L. All authors have read and agreed to the published version of the manuscript.

Funding: This study was funded by “Development of Decision Supporting Framework to Enhance Natural Capital Sustainability (RR2015-11)" and "An Integrated Assessment to Environmental Valuation via Impact Pathway Analysis (GP2021-09)", supported by the Korea Environment Institute.

Institutional Review Board Statement: Not applicable.

Informed Consent Statement: Not applicable.

Conflicts of Interest: The authors declare no conflict of interest.

\section{References}

1. United Nations Convention on Biological Diversity (1992): Article 2. Use of Terms. 1992. Available online: https://www.cbd.int/ doc/legal/cbd-en.pdf (accessed on 25 March 2020).

2. Millennium Ecosystem Assessment. Ecosystems and Human Well-Being: Synthesis; Island Press: Washington, DC, USA, 2005.

3. Díaz, S.; Fargione, J.; Chapin, F.S.; Tilman, D. Biodiversity Loss Threatens Human Well-Being. PLoS Biol. 2006, 4, e277. [CrossRef] 
4. OECD. OECD Environmental Outlook to 2050; OECD Publishing: Paris, France, 2012. [CrossRef]

5. UN Environment. Glob. Environ. Outlook-GEO-6: Healthy Planet, Healthy People; UN Environment: Nairobi, Kenya, 2019. [CrossRef]

6. IPBES. Summary for Policymakers of the IPBES Global Assessment Report on Biodiversity and Ecosystem Services; IPBES Secretariat: Born, Germany, 2019.

7. Secretariat of the Convention on Biological Diversity. Global Biodiversity Outlook 2; Convention on Biological Diversity: Montreal, QC, Canada, 2006.

8. Primack, R. A Primer of Conservation Biology, 2nd ed.; Sinauer Associates: Sunderland, UK, 2000.

9. Walther, G.R.; Post, E.; Convey, P.; Menzel, A.; Parmesan, C.; Beebee, T.J.; Fromentin, J.M.; Hoegh-Guldberg, O.; Bairlein, F. Ecological Responses to Recent Climate Change. Nature 2002, 416, 389-395. [CrossRef] [PubMed]

10. Yuk, G.; Kang, M.; Kang, W.; Go, I.; Bae, S.; Lee, M.; Choi, K.; Heo, J.; Lee, D. Biodiversity and Threat Factors, the Foundation of Ecosystem Services and Human Culture. J. Environ. 2010, 49, 1-25.

11. Hall, L.S.; Krausman, P.R.; Morrison, M.L. The Habitat Concept and a Plea for Standard Terminology. Wildl. Soc. Bull. 1997, 25, 173-182.

12. Wilcove, D.S.; Rothstein, D.; Dubow, J.; Phillips, A.; Losos, E. Quantifying Threats to Imperiled Species in the United States. BioScience 1998, 48, 607-615. [CrossRef]

13. Myers, N.; Mittermeier, R.A.; Mittermeier, C.G.; Da Fonseca, G.A.B.; Kent, J. Biodiversity Hotspots for Conservation Priorities. Nature 2000, 403, 853-858. [CrossRef] [PubMed]

14. OECD. Environmental Indicators for Agriculture: Methods and Results; OECD Publications: Paris, France, 2001.

15. Primack, R. A Primer of Conservation Biology, 3rd ed.; Sinauer Associates: Sunderland, UK, 2004.

16. Ferrier, S. Mapping Spatial Pattern in Biodiversity for Regional Conservation Planning: Where to From Here? Syst. Biol. 2002, 51, 331-363. [CrossRef]

17. World Resources Institute. World Resources 1994-1995: A Guide to the Global Environment; Oxford University Press: New York, NY, USA, 1994.

18. Beazley, K.; Smandych, L.; Snaith, T.; MacKinnon, F.; Austen-Smith, P.; Duinker, P. Biodiversity Considerations in Conservation System Planning: Map-Based Approach for Nova Scotia, Canada. Ecol. Appl. 2005, 15, 2192-2208. [CrossRef]

19. Hayward, L.S.; Busch, D.S. Conservation Behavior and Endocrinology. In Encyclopedia of Animal Behavior; Academic Press: London, UK, 2010.

20. Ah-King, M. Flexible Mate Choice. In Encyclopedia of Animal Behavior; Academic Press: London, UK, 2010.

21. Jeltsch, F.; Moloney, K.A.; Schwager, M.; Körner, K.; Blaum, N. Consequences of Correlations between Habitat Modifications and Negative Impact of Climate Change for Regional Species Survival. Agric. Ecosyst. Environ. 2011, 145, 49-58. [CrossRef]

22. Nelson, E.; Mendoza, G.; Regetz, J.; Polasky, S.; Tallis, H.; Cameron, D.R.; Chan, K.M.; Daily, G.C.; Goldstein, J.; Kareiva, P.M.; et al. Modeling Multiple Ecosystem Services, Biodiversity Conservation, Commodity Production, and Tradeoffs at Landscape Scales. Front. Ecol. Environ. 2009, 7, 4-11. [CrossRef]

23. Polasky, S.; Nelson, E.; Pennington, D.; Johnson, K.A. The Impact of Land-Use Change on Ecosystem Services, Biodiversity and Returns to Landowners: A Case Study in the State of Minnesota. Environ. Resour. Econ. 2011, 48, 219-242. [CrossRef]

24. Terrado, M.; Sabater, S.; Chaplin-Kramer, B.; Mandle, L.; Ziv, G.; Acuña, V. Model Development for the Assessment of Terrestrial and Aquatic Habitat Quality in Conservation Planning. Sci. Total Environ. 2016, 540, 63-70. [CrossRef]

25. Ntshane, B.S.; Gambiza, J. Habitat Assessment for Ecosystem Services in South Africa. Int. J. Biodivers. Sci. Ecosyst. Serv. Manag. 2016, 12, 242-254. [CrossRef]

26. Salata, S.; Ronchi, S.; Arcidiacono, A.; Ghirardelli, F. Mapping Habitat Quality in the Lombardy Region, Italy. One Ecosyst. 2017, 2, e11402. [CrossRef]

27. Xu, L.; Chen, S.; Xu, Y.; Li, G.; Su, W. Impacts of Land-Use Change on Habitat Quality during 1985-2015 in the Taihu Lake Basin. Sustainability 2019, 11, 3513. [CrossRef]

28. Terrado, M.; Sabater, S.; Acuña, V. Identifying Regions Vulnerable to Habitat Degradation under Future Irrigation Scenarios. Environ. Res. Lett. 2016, 11, 114025. [CrossRef]

29. Nematollahi, S.; Fakheran, S.; Kienast, F.; Jafari, A. Application of InVEST Habitat Quality Module in Spatially Vulnerability Assessment of Natural Habitats (Case Study: Chaharmahal and Bakhtiari Province, Iran). Environ. Monit. Assess. 2020, $192,1-17$. [CrossRef] [PubMed]

30. Wang, Y.; Fu, B.; Colvin, C.; Ennaanay, D.; McKenzie, E.; Chen, M. Mapping Ecosystem Function Conservation Areas to Integrate Ecosystem Services into Land Use Plans in Baoxing County, China. 2010. Available online: http:/ /www.teebweb.org/wp-content/uploads/ 2013/01/Mapping-conservation-areas-for-ecosystem-services-in-land-use-planning-China.pdf (accessed on 17 March 2021).

31. Duarte, G.T.; Ribeiro, M.C.; Paglia, A.P. Ecosystem Services Modeling as a Tool for Defining Priority Areas for Conservation. PLOS ONE 2016, 11, e0154573. [CrossRef]

32. Zhu, C.; Zhang, X.; Zhou, M.; He, S.; Gan, M.; Yang, L.; Wang, K. Impacts of Urbanization and Landscape Pattern on Habitat Quality Using OLS and GWR Models in Hangzhou, China. Ecol. Indic. 2020, 117, 106654. [CrossRef]

33. Gibson, D.M.; Quinn, J.E. Application of Anthromes to Frame Scenario Planning for Landscape-Scale Conservation Decision Making. Land 2017, 6, 33. [CrossRef]

34. Hong, H.; Lee, H.; Yun, I. Foundational Study on Biosafety Legislation; Korea Environment Institute: Sejong, Korea, 2015. 
35. Hallasan Mountain Research Institute. Halla Mountain National Park Natural Resource Survey; Jeju Special Self-Government Province: Jeju, Korea, 2012.

36. Jeon, S.; Hong, H.; Kang, S. Simulation of Urban Growth and Urban Living Environment with Release of the Green Belt. Sustainability 2018, 10, 3260. [CrossRef]

37. Sharp, R.; Tallis, H.T.; Ricketts, T.; Guerry, A.D.; Wood, S.A.; Chaplin-Kramer, R.; Nelson, E.; Ennaanay, D.; Wolny, S.; Olwero, N.; et al. InVEST 3.9.0. User's Guide. 2021. Available online: https://invest-userguide.readthedocs.io/_/downloads/en/3.9.0/pdf/ (accessed on 17 March 2021).

38. Zhong, L.; Wang, J. Evaluation on Effect of Land Consolidation on Habitat Quality Based on InVEST Model. Trans. Chin. Soc. Agric. Eng. 2017, 33, 250-255. [CrossRef]

39. Gao, Y.; Ma, L.; Liu, J.; Zhuang, Z.; Huang, Q.; Li, M. Constructing Ecological Networks Based on Habitat Quality Assessment: A Case Study of Changzhou, China. Sci. Rep. 2017, 7, 46073. [CrossRef] [PubMed]

40. Park, C.; Oh, G.; Oh, C.; Han, B. Development Guidelines for the Construction of an Urban Ecological Axis; Korea Environment Institute: Seoul, Korea, 2007.

41. Jang, K. A Study on the Construction of the Keumgang West Sea Basin Green Belt Network Using Nearest Feature Model. Kor. J. Land Arch. 2007, 35, 56-63.

42. Kellner, C.J.; Brawn, J.D.; Karr, J.R. What Is Habitat Suitability and How Should It Be Measured? In Wildlife 2001: Populations; Springer: Berlin/Heidelberg, Germany, 2001; pp. 476-488.

43. National Inventory of Natural Heritage. Available online: https://inpn.mnhn.fr/programme/sensibilite-ecologique?lg=en (accessed on 12 December 2020).

44. Lee, H.; Kim, C.; Hong, H.; Noh, Y.; Kang, S.; Kim, J.; Shin, S.; Lee, S.; Kim, T.; Kang, J. Development of Decision Supporting Framework to Enhance Natural Capital Sustainability: Focusing on Ecosystem Service Analysis; Korea Environment Institute: Sejong, Korea, 2015.

45. Jeju Green Environment. Mid-Term Basic Plan for Environment Conservation of Jeju Special Self-Government Province; Jeju Special Self-Government Province: Jeju, Korea, 2016.

46. Koo, K.; Park, S. Prioritizing Ecologically Important Areas Under Land-Use Changes in Jeju Island, Jeju, Korea. J. Korean Geogr. Soc. 2020, 55, 253-264.

47. Lee, D.; Jeon, S.W. Estimating Changes in Habitat Quality through Land-Use Predictions: Case Study of Roe Deer (Capreolus pygargus Tianschanicus) in Jeju Island. Sustainability 2020, 12, 10123. [CrossRef]

48. Kang, H. Jeju Vision for the Future and Special Law on Jeju Island. World Environ. Isl. Stud. 2017, 7, $237-256$.

49. Lee, C.; Jang, G.; Ryu, T.; Choi, B. A Study on Vascular Plants, Distribution Status and Management Plans of the Cactus Habitat (No. 429 Natural Monument) in Wolryung-ri, Jeju Island. J. Korean Inst. Tradit. Landsc. Archit. 2018, 36, 55-66. [CrossRef]

50. Oh, S.; Kim, B.W.; Kwak, S.; Park, H.; Rim, H.; Song, U. Spatial Distribution, Growth Conditions and Local Utilization for Conservation Strategy of an Endangered Species Azolla japonica. J. Plant Biol. 2021. [CrossRef]

51. Kang, H.; Kim, C.; Kim, E. Human Influence, Regeneration, and Conservation of the Gotjawal Forests in Jeju Island, Korea. J. Mar. Isl. Cultures 2013, 2, 85-92. [CrossRef]

52. Keith, B.; Kim, E.; Yang, Y.; Lee, S. A Study on Restoration Plans of Jeju Hanon Maar Crater. World Environ. Isl. Stud. 2014, 4, 45-82.

53. Byun, K.H.; Kang, E.J.; Kim, K.H. Environment Management for Sustainability of Hallasan National Park in Jeju Island, Korea. Adv. Mater. Res. 2014, 905, 334-338. [CrossRef] 